Table 1. Patient characteristics and adverse events by treatment group

\begin{tabular}{lcc}
\hline & Anti-TNF & JAKi \\
\hline Mean age start of treatment (SD), yrs & $50.8(12.6)$ & $57.6(11.9)$ \\
Female, $\mathrm{n}(\%)$ & $3122(58.8)$ & $392(79.5)$ \\
Disease duration, median (IQR) & $7.0(2.7-13.7)$ & $9.9(4.9-16.8)$ \\
First line biologic, $\mathrm{n}(\%)$ & $2614(49.3)$ & $117(23.7)$ \\
Rheumatoid Arthritis & $1385(41.1)$ & $339(95.2)$ \\
Ankylsosing Spondylitis & $1031(30.6)$ & $1(0.3)$ \\
Psoriatic Arthritis & $957(28.4)$ & $16(4.5)$ \\
DAS28-ESR & $4.3(1.4)$ & $4.7(1.4)$ \\
Survival first year (IC 95\%) & $73.3(71.9-74.6)$ & $69.7(66.0-73.0)$ \\
Charlson Index, mean (SD) & $1.9(1.3)$ & $2.3(1.6)$ \\
Reason to stop therapy (n)* & & \\
$\quad$ Lack of efficacy & $1534(53.2)$ & $57(58.8)$ \\
Adverse event & $723(25.1)$ & $33(34.0)$ \\
Adverse events (AE) & & \\
Serious infections & $14.2(12.4-16.2)$ & $33.2(19.3-57.3)$ \\
Herpes zoster & $5.7(4.6-7.1)$ & $12.8(5.3-30.7)$ \\
Tuberculosis & $0.7(0.4-1.3)$ & $0.0(0.0-0.0)$ \\
Malignancy/Neoplasia & $10.2(8.7-11.9)$ & $15.3(6.9-34.2)$ \\
Cardiac events & $13.9(12.2-16.0)$ & $30.7(17.4-54.0)$ \\
Gl perforation & $1.2(0.8-1.9)$ & $10.2(3.8-27.3)$ \\
Vascular events & $9.8(8.3-11.5)$ & $25.6(13.8-47.5)$ \\
\hline
\end{tabular}

${ }^{*}$ Data show the incidence rate ratio per 1000 patient-years (PYs; $95 \% \mathrm{Cl}$ )

Conclusion: Serious infections and herpes zoster tend to be more frequent in patients on JAKi. However patients on JAKi were older, presented higher comorbidity and have a longer disease duration.

Disclosure of Interests: None declared

DOI: 10.1136/annrheumdis-2021-eular.2645

\section{OP0124 EFFECTS OF NINTEDANIB IN PATIENTS WITH PROGRESSIVE FIBROSING INTERSTITIAL LUNG DISEASE ASSOCIATED WITH RHEUMATOID ARTHRITIS (RA-ILD) IN THE INBUILD TRIAL}

C. Kelly', E. Matteson ${ }^{2}$, M. Aringer ${ }^{3}$, G. R. Burmester ${ }^{4}$, H. Mueller ${ }^{5}$, L. Moros ${ }^{6}$, K. Rohr ${ }^{6}$, M. Kolb ${ }^{7}$ on behalf of the INBUILD Trial Investigators. ${ }^{1}$ Newcastle University, Institute of Cellular Medicine, Newcatle upon Tyne, United Kingdom; ${ }^{2}$ Mayo Clinic College of Medicine and Science, Division of Rheumatology, Rochester, United States of America; ${ }^{3}$ University Medical Center \& Faculty of Medicine, TU Dresden, Rheumatology, Medicine III, Dresden, Germany; ${ }^{4}$ Charité-University Medicine Berlin, Department of Rheumatology and Clinical Immunology, Berlin, Germany; ${ }^{5}$ Boehringer Ingelheim Pharma GmbH \& Co. KG Biostatistics and Data Sciences, Biberach, Germany; ${ }^{6}$ Boehringer Ingelheim International GmbH, TA Inflammation Med, Ingelheim am Rhein, Germany; ${ }^{7}$ McMaster University and St. Joseph's Healthcare, Department of Medicine, Hamilton, Canada

Background: In the INBUILD trial in subjects with progressive fibrosing ILDs other than idiopathic pulmonary fibrosis (IPF), nintedanib reduced the rate of decline in FVC (mL/year) over 52 weeks by $57 \%$ compared with placebo.

Objectives: To assess the rate of decline in FVC in subjects with RA-ILD in the INBUILD trial.

Methods: Subjects in the INBUILD trial had a chronic fibrosing ILD other than IPF, reticular abnormality with traction bronchiectasis (with or without honeycombing) of $>10 \%$ extent on high-resolution computed tomography (HRCT), forced vital capacity (FVC) $\geq 45 \%$ predicted, diffusing capacity of the lungs for carbon monoxide $\geq 30 \%-<80 \%$ predicted, and met criteria for progression of ILD within the 24 months before screening, despite management deemed appropriate in clinical practice. Patients taking stable doses of approved medications to treat RA or connective tissue disease could participate, except that the protocol excluded those taking azathioprine, cyclosporine, mycophenolate mofetil, tacrolimus, rituximab, cyclophosphamide, or oral glucocorticoids $>20 \mathrm{mg} /$ day. We analysed the rate of decline in FVC (mL/year) over 52 weeks and adverse events in subjects with RA-ILD.

Results: Of 663 subjects who received trial medication, 89 had RA-ILD (42 nintedanib, 47 placebo), of whom $60.7 \%$ were male, $64.0 \%$ were current or former smokers, $86.5 \%$ had a usual interstitial pneumonia (UIP)-like pattern on HRCT; $93.3 \%$ had received confirmation of their RA diagnosis from a rheumatologist. At baseline, $21.3 \%$ of subjects were taking biologic disease-modifying anti-rheumatic drugs (DMARDs), $53.9 \%$ were taking non-biologic DMARDs and $73.0 \%$ were taking glucocorticoids $(\leq 20 \mathrm{mg} /$ day prednisone or equivalent). At baseline, mean (SD) age was 66.9 (9.6) years, time since RA diagnosis was 9.9 (9.4) years, time since ILD diagnosis was 3.6 (3.2) years, FVC was 71.5 (16.2) \% predicted and C-reactive protein was 13.7 (22.5) $\mathrm{mg} / \mathrm{L}$. The adjusted mean (SE) rate of decline in FVC over 52 weeks was -82.6 (41.3) $\mathrm{mL} / \mathrm{year}$ in the nintedanib group versus -199.3 (36.2) $\mathrm{mL} /$ year in the placebo group (difference $116.7 \mathrm{~mL} /$ year [95\% Cl 7.4, 226.1]; nominal $\mathrm{p}=0.037$ ), consistent with findings in the overall trial population (Figure). As in the overall trial population, the most common adverse event in subjects with RA-ILD was diarrhoea (reported in $54.8 \%$ of the nintedanib group and $25.5 \%$ of the placebo group). Adverse events led to permanent discontinuation of trial drug in $19.0 \%$ of subjects in the nintedanib group and $12.8 \%$ of subjects in the placebo group.

Conclusion: In the INBUILD trial, nintedanib slowed the rate of decline in FVC in patients with progressive fibrosing RA-ILD, with adverse events that were manageable for most patients. The efficacy and safety of nintedanib in subjects with RA-ILD were consistent with those observed in the overall trial population.

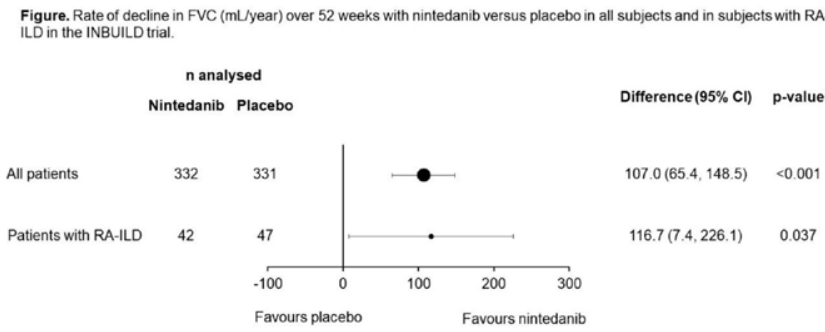

Acknowledgements: The INBUILD trial was funded by Boehringer Ingelheim. Medical writing support was provided by Fleishman Hillard Fishburn, London, UK. The authors meet criteria for authorship as recommended by the International Committee of Medical Journal Editors (ICMJE).

Disclosure of Interests: Clive Kelly Speakers bureau: Boehringer Ingelheim, Consultant of: Boehringer Ingelheim, Eric Matteson Speakers bureau: Boehringer Ingelheim, Consultant of: Boehringer Ingelheim and Gilead Sciences, Grant/research support from: Sun Pharmaceuticals and Pfizer, Martin Aringer Speakers bureau: AbbVie, AstraZeneca, Bristol-Myers Squibb, Boehringer Ingelheim, Chugai, Gilead, GlaxoSmithKline, HEXAL, Lilly, MSD, Novartis, Pfizer, Roche, Sanofi and UCB, Consultant of: AbbVie, AstraZeneca, Bristol-Myers Squibb, Boehringer Ingelheim, GlaxoSmithKline, Lilly, Merck Sharp \& Dohme, Novartis, Pfizer, Roche, Sanofi and UCB, Gerd Rüdiger Burmester Speakers bureau: AbbVie, Bristol-Myers Squibb, Boehringer Ingelheim, Gilead, Lilly, Merck Sharp \& Dohme, Pfizer, Roche and Sanofi, Consultant of: AbbVie, Bristol-Myers Squibb, Boehringer Ingelheim, Gilead, Lilly, Merck Sharp \& Dohme, Pfizer, Roche and Sanofi, Heiko Mueller Employee of: Currently an employee of Boehringer Ingelheim, Lizette Moros Employee of: Currently an employee of Boehringer Ingelheim, Klaus Rohr Employee of: Currently an employee of Boehringer Ingelheim Martin Kolb Consultant of: Algernon, Boehringer Ingelheim, Pieris Pharmaceuticals and Roche, Grant/research support from: Boehringer Ingelheim, Pieris Pharmaceuticals and Prometic DOI: 10.1136/annrheumdis-2021-eular.969

\section{OP0125 TOFACITINIB IN RHEUMATOID ARTHRITIS- ASSOCIATED INTERSTITIAL LUNG DISEASE: EFFICACY AND SAFETY ANALYSIS FROM TREASURE REAL-LIFE DATA}

U. Kalyoncu ${ }^{1}$, E. Bilgin ${ }^{1}$, A. Erden ${ }^{2}$, H. Satıs ${ }^{3}$, A. Tufan ${ }^{3}$, E. Tekgoz ${ }^{4}$, A. Ateș ${ }^{5}$, B. N. Coşkun ${ }^{6}$, B. Yağız ${ }^{6}$, O. Küçükşahin ${ }^{7}$, V. Yazısız ${ }^{8}$, G. Kimyon ${ }^{9}$, C. Bes ${ }^{10}$, A. İ. Ertenli ${ }^{1}$, S. Kiraz ${ }^{1} .{ }^{1}$ Hacettepe University, Internal Medicine, Rheumatology, Ankara, Turkey; ${ }^{2}$ Ankara City Hospital, Internal Medicine, Rheumatology, Ankara, Turkey; ${ }^{3}$ Gazi University, Internal Medicine, Rheumatology, Ankara, Turkey; ${ }^{4}$ University of Health Sciences Turkey, Gulhane Faculty of Medicine, Internal Medicine, Rheumatology, Ankara, Turkey; ${ }^{5}$ Ankara University, Internal Medicine, Rheumatology, Ankara, Turkey; ${ }^{6}$ Uluda ğ University, Internal Medicine, Rheumatology, Bursa, Turkey; ${ }^{7}$ Yıldırım Beyazıt University, Internal Medicine, Rheumatology, Ankara, Turkey; ${ }^{8}$ Akdeniz University, Internal Medicine, Rheumatology, Antalya, Turkey; ${ }^{9}$ Mustafa Kemal University, 